\title{
The role and meaning of interim housing in Housing First programs for people experiencing homelessness and mental illness
}

\author{
Zerger, Suzanne; Francombe Pridham, Katherine; Jeyaratnam, \\ Jeyagobi; Connelly, Jolynn; Hwang, Stephen; O'Campo, Patricia; \\ Stergiopoulos, Vicky
}

Version Post-Print/Accepted Manuscript

Citation Zerger, Suzanne; Francombe Pridham, Katherine; Jeyaratnam, Jeyagobi; (published version) Connelly, Jolynn; Hwang, Stephen; O'Campo, Patricia; Stergiopoulos, Vick. (2014). The role and meaning of interim housing in Housing First programs for people experiencing homelessness and mental illness. American Journal of Orthopsychiatry, Vol 84(4), 431-437. http://dx.doi.org/10.1037/h0099842

Publisher's Statement This article may not exactly replicate the authoritative document published in the APA journal. It is not the copy of record.

PsycINFO Database Record (c) 2017 APA. All rights reserved. accepted manuscript) because you cannot access the published version, then cite the TSpace version in addition to the published version using the permanent URI (handle) found on the record page. 


\section{INTRODUCTION / BACKGROUND}

The Housing First (hereafter 'HF') model for individuals experiencing chronic homelessness and mental illness is based on the premise that this populationwill have superior housing and recovery outcomes if given immediate accessto permanent, independenthousing of their choice, and provided with flexible case management services. By design, Housing First stands in contrast tomore traditional 'treatment first' transitional housing models which specifytreatment prerequisites, such as adherence to mental health treatment or abstinence from alcohol or drugs, prior to gaining access to permanent housing(Lincoln, Plachta-Elliott et al. 2009).Given thegrowing evidence on its favorable outcomes and cost effectiveness in the US and abroad, HF is increasingly seen as an alternative to and argument against these traditional programs.Within this context, it is important that the elements and implementation challenges of the HF model be clearly understood and articulated. The present study explores a largely unexamined component of the HF model, the need for and meaning of temporary residential settings - what we term "interim housing" - a place to stay while waiting to securepermanent housing. . "Interim housing" hererefers to temporary housing during transitional periods which occur within the HF model; it is not to be confused with transitional housingprograms whichtypically require prerequisites to be met to determine housing readiness and more commonly fall within a 'treatment first'approach.

\section{Housing Stability in the Housing First Model}

Housing tenure and stability are chief priorities of $\mathrm{HF}$, and among its most promising outcomes: one U.S. study, for example, found $88 \%$ ofhomeless persons with psychiatric disabilities housed in a Housing First program were still housed five years after entering the program(Tsemberis and Eisenberg 2000), and a Canadian HF program which housed people 
directly from the street showed $87 \%$ remaining in their homes after one year (City of Toronto 2007; 2013).But as several researchers have pointed out, residential stability for chronically homeless persons needs to beunderstood as a dynamic process, not a static condition, given the daunting nature of community reintegration\{Lipton, 2000 \#514\}\{Lincoln, 2009 \#709\}\{Levitt, $2012 \# 670$ \}. A review of HF programs reported, for example, that only about half of the consumers spent every night in their unit during the first year, and another study found HF consumers were stably housed about three-quarters of the time ( $\left\{O^{\prime}\right.$ Connell, $2006 \# 376$ Pearson, $2009 \# 371$ \} \{adgett, $2006 \# 373$ \}. One author described housing stability in the Housing Firstmodel as 'an iterative process' (Pearson, Montgomery et al. 2009), p.415, while another review of housing models targeting this population noted that housing placement should be viewed as a stage in 'an ongoing process of community integration'(Lipton, Siegel et al. 2000), p.486.

Ensuring housing stability requires case managers to provide extensive housing and rehabilitation support, such as helping consumers adjust to living independently to ward off housing disruption, pursuing recovery goals, and assisting them in finding housing in the event of housing loss (Stefancic and Tsemberis 2007). No time limit is typically placed on such services.

\section{Interim Housing Needs: Delays and Relocations}

Housing stability in the HF model relies onflexible case management services because consumers frequently have complex needs which complicate finding and maintaining housing and community integration,. Some delays in initial and subsequent housing placements, in this context, can create a need for interim housing options.A brief discussion of interim housing in aHF bookabout the pioneer HF program (Pathways to Housing, Inc. in New York) suggeststhese 
temporary settings (such as YMCAs) may be needed for consumers recruited directly from the streets or a public place, or jail or prison, but may not be necessary for those recruited from institutions (e.g. psychiatric hospital or shelter) who can continue to reside there while waiting for their initial housing unit(Tsemberis 2010), p.50-1). It should be noted, however, that even consumers in the latter cases may require interim housing if they are discharged suddenly, for example, or are barred from shelters. The author also notes advantages to interim housing used during delays in initial placement, including allowing consumers time to rest and enabling case managers to build trust and easily locate and maintain contact withthem(Tsemberis 2010). Indeed, a comprehensive review of $23 \mathrm{HF}$ programs found that all but two used interim housing prior to initial placements (Pearson, Locke et al. 2007). Some of these programs used hotels, YMCAs or other similar settingsfor consumers who needed to wait until a unit became available. Others, however, relied on interim housing placements regularly for consumers to stabilize (e.g. from hospitalization) and for case managers to identify housing that would best serve their needs (p.102).

Interim housing may also be needed during post-placement relocations, a common deviation from continuous residency. In the Streets-to-Home study\{City of Toronto, 2007 \#515\}, one-third of those surveyed had moved at least once after being housed (half of those who had been housed more than a year), and a review of HF programs found between one-third and threequarters of consumers changed housing within their first twelve months (City of Toronto 2007; Pearson, Montgomery et al. 2009). Some reasons for relocations include problems with landlords, difficulties with roommates or relationship break-ups, and desires to change unit and/or location (City of Toronto 2007). 
In each of these scenarios - prior to initial housing or during housing transitionspostplacement - there can be short or long-term gaps in housing. Given the need for continuous service engagement, the published research suggests that interim housing situationsmayenable the service providers to maintain contact and support long-term recovery goals. To achieve the best outcomes in the HF model then, not only requires continuous service provision - including housing support services - but also interim settings to minimize service disruptionsduring anticipatedhousing gaps. While the latter may not be an essential component of HF, it is likely needed for most programs. To date, though, little is known abouthow these interim situations are addressed in practice, how they are experiencedby providers and consumers, or what (if any) effects they haveon service engagement. The aim of this exploratory study is to provide a better understanding of theuse of interim housing in HF, the types of interim housing commonly used, and the experiences with interim situations from the perspectives of consumers, case managers, and housing workers of a HF program.

\section{METHODOLOGY}

Given the limited literature and understanding of interim situations in $\mathrm{HF}$, qualitative methods are best suited to our study aims. This study was conducted by the Centre for Research on Inner City Health at St. Michael's Hospital in Toronto during the course of the At Home/Chez Soi Research Demonstration Project in Mental Health and Homelessness (hereafter 'At Home'), a randomized controlled trial launched in 2008 in five Canadian cities (Vancouver, Winnipeg, Toronto, Montreal and Moncton) to assess the effectiveness and cost effectiveness of HF in the Canadian context(For detailed information about the Toronto site of At Home, see (Hwang, Stergiopoulos et al. 2012; Stergiopoulos 2012). Toronto's At Home participants were recruited from a variety of organizations serving people experiencing homelessness; eligibility criteria 
included being absolutely homeless or precariously housed, being 18 years or older, and having a serious mental disorder with or without a co-occurring substance related disorder. Precariously housed refers to those whose primary residence was a Single Room Occupancy (SRO), rooming house or hotel/motel; to reach eligibility these individuals also had to have two or more episodes of absolute homelessness in the prior year. "Serious mental disorders" were identified on the basis of functional disability in two or more activities of daily living andresults of the Mini International Neuropsychiatric Interview(Sheehan, Lecrubier et al. 1998). Both At Home and this supplemental study were approved by the Research Ethics Board at St. Michael's Hospital, Toronto.

\section{Study Samples and Data Sources}

Over four-fifths ( $\mathrm{n}=253$ or $84.1 \%$ ) of Toronto's 301 At Home study participants randomized to the HF intervention obtained housing within four months, nine percent $(n=27)$ obtained housing between four months and one year, and seven percent $(n=21)$ remained unhoused after more than one year .Furthermore, approximately one-third (34\%) of the sample had relocated or requested a transfer at least once during their first year in housing. For this study, we recruited a sample of 48 participants, including 25 consumer-participants who were randomized to receive HF through the At Home project and 23 service and housing providers involved in the At Home project. We randomly selected ten consumers from the list of participants who experienced delays in initial housing placement of four to twelve months, and ten among those with one or more relocation (or request for relocation). We used convenience sampling to recruit five participants who had remained unhoused after one year. Convenience sampling was necessary in this instance because these individuals were difficult to locate and engage. 
Consumers in this sample closely resemble those in the Toronto At Home study sample as a whole: two-thirds were male, the average age was 42 years, and a slight majority (60\%) had been homeless for three or more years. Consumers participating in this study received a \$25honorarium and two transit tokens.

Semi-structured in-person interviews were conducted with consumers by a single researcher. Interviews lasted approximately one hour. The same researcher also facilitated four focus groups with a total of 15 case managers and three housing workers, and in-person interviews with the five managers of case management and housing placement teams. Interview and focus group protocols asked both participants and their providers about their perceptions of factors related to delays or relocations, choices of housing that were available/offered, as well as experiences with and impacts of time spent waiting for permanent independent housing.

\section{Analysis}

Interviews and focus group sessions for the 48 participants in the study were audio-taped and transcribed; all files were imported into NVivo 9.2 software to aid in organizing, coding, and visualizing the data. Two qualitative researchers collaborated on data coding. The primary researcher, who conducted the interviews and facilitated the focus groups, drafted a list of categories associated with each of the protocol topic areas to begin organizing the data. This researcher then conducted line-by-line coding of three transcripts, one consumer and one key informant interview, and a provider focus group, to generate a list of codes within these categories and begin the search for themes. A second researcher "double-coded" the same transcripts, and then worked together to refine and revise the codes to ensure mutual understandings and definitions of the coding schema. The primary researcherthen coded the remaining transcripts, joined by a senior qualitative analyst. The senior analyst reviewed the 
codes, read the transcripts and listened to a sample of audiofiles, then worked closely with the primaryresearcher to refine the codes and discuss emerging themes that cross-cut the subgroups.Following the process ofthematic analysis, they worked together with the study principalinvestigator to review and refine the themes, gaining clarity and building consistency in the story told within each theme(Braun and Clarke 2006). Throughout the process, the primary analyst used NVivo'smemos feature to document anomalies and capture emerging themes within and among the subgroups.

\section{FINDINGS}

As noted above, our study focuses on the relatively small minority of participants who experienced delays (of four months or more) and multiple relocations during the first year in a HF program.In a separate study, focused on factors associated with housingdelays and relocations, consumer choice (and provider adherence to that choice), in the context of a limited supply of affordable housing, emerged as a primary contributor\{Pridham, $2013 \# 626$ \} In Toronto, for example, many of the participants desired to live in downtown locations close to services, yet affordable market rent units were most scarce in these locations..The identified need for interim housing in that context was therefore not surprising, as the program prioritized consumer choice.

When we explored experiences with interim housing, two general themes emerged : 1) the volatility of the interim situations; and, 2) effects of interim situations on continuous service engagement and therapeutic relationships.

\section{Volatility of Interim Situations}

Interim situations tended to be marked by volatility, asconsumers continued to move frequently or reside in multiple places. Given expectations ofimmediate access topermanent 
independent housing,feelings of frustration and anxiety were piqued during those times. $\underline{\text { Itinerant Lifestyles }}$

On the whole, interim situations for these consumers closely resembled their preenrollment lives, marked by itinerant lifestyles and/or residency in non-optimal settings. Many continued to live how and where they had prior to being enrolled in the project. Comments included:'All over the place. Couch Surfing, ...Y You name it, I've been there;'‘staying in coffee shops most of the night and things like that;' and, 'I wentback and forth, you know what I mean?One month there, one month there, one month there.'Many remained in (or moved to) homeless shelters or short-term crisis accommodations and a few stayed with friends or family; though none of these options were ideal, individuals chose the best among available alternatives. For example, this woman opted to stay in her 'usual' homeless shelter: 'So many shelters I've been, and then I don't want to change one to another one because, ...just so tired,;' but another chose not to stay in the shelter any longer: 'I can't take living inside the [homeless shelter] too much.' Most consumers experienced more than one of these options, especially if their interim situation was unexpected or especially long. Onewoman, for example, stayed in a treatment facility for mental health and addictions for three weeks, followed by two weeks in a hotel paid for by the project, and notes thateventually she, with her child and partner, 'went to....stay with my mom, because we couldn't find an apartment yet. And she had a small one-bedroom, so there was all of us in a tiny one-bedroom.'

\section{$\underline{\text { AddressingFeelings, Managing Expectations }}$}

Because consumersexpectedimmediate access to permanent independent housing, these interim periods were weighted by disappointment. 'It's kind of rough. I mean, thinking you have a place and then you don't, you know. It's just depressing, I guess.' This consumer who 
experienced a long delay waiting for a unit in a specific downtown neighborhood with low vacancy rates commented 'They put me up in emergency housing... It's like I had housing but I was homeless. It was bullshit.'The promise of housing changed their perspectives on their preenrollment lives. This consumer lived in a homeless shelter for many months after enrollment: 'It's fine. It's just that I, I just want a place of my own, because I've been sharing ...'Those who were in an interim situation while waiting to be transferred had similar sentiments. This woman stayed with her mother between looking for apartments after getting evicted due to "paranoid" behavior: 'I was tired of it. Tired of the moving and all that stuff...Because, you know, all I want is a place to live.'

Because housing took longer than anticipated for these participants, or they experienced delays while awaiting a transfer, feelings of frustration, anxiety, and depression were intensified. They described being 'anxious' and used words like 'frustrating', 'worrying', 'depressing', and 'miserable' to describe the wait. The longer the interim period endured, the more likely they feared they would remain in limbo and never access the promised housing. As one man waiting in a shelter commented, 'Waiting's always not good. It comes worrying sometimes, you know. Are these people serious? Are they looking for me? Why do I have to wait? You ask all of these questions.'This man opted to reside in a hotel in a remote area during an interim wait; while staff considered it a 'wise decision' because he would be distanced from drug activity, he described the experience this way: “Depressing. It wasn't a good experience. I didn't really go anywhere; I just locked myself up in the room. ... couldn't go to the food bank. I could not travel."

The vulnerability of consumers during their interim stays did not go unnoticed by service providers. This case manager expressed concern about the man staying in the remotely located hotel: 'he was really frustrated and depressed and he was using alcohol in the morning. [He] is 
not usually like that. He really struggled with depression. He kind of felt that he was incarcerated in one corner.'This case manager worried about another man residing ina rundown hotel: 'Every time I visit him, he's complaining about bed bugs...or somebody has stolen his scarf. ...that was really painful for him. Why put him in that sort of environment,?You're actually creating more stresses for the person.'Service providers werealso stressed during the interim waits. These case managers described feeling as frustrated as the consumers about the delay: 'So their stress is channelled to me;' and, 'there's definitely been some frustration for a few people but we're frustrated too.'Their knowledge about the importance and benefits of housing for these consumers added to their impatience; this housing worker comments: 'It was justknowing that if he could just find this housing, he would be good, right?Like, things would start to be good for this guy. It played on me...?'

Interim situations for these consumers typically resembled their pre-enrollment lives, marked by repeated moves and/or residency in non-optimal settings; they lived in shelters, changed residences frequently, or were placed in hotels or rooming houses. But the anticipation of immediate access to permanent housing made their waits fraught with frustration, unease and worry. The longer the wait, the more vulnerable they felt to the possibility of being forgotten and losing the promised permanent housing altogether. Service providers engaged with consumers throughout these periods, but were also concerned about the impact on consumers' mental health and well-being.

\section{$\underline{\text { Effects on Therapeutic Relationships and Continuous Service Engagement }}$}

The unique volatility and the singular focus on accessing permanent housing during interim situations affected therapeutic relationships and service engagement patterns. In general, 
they posed special barriers and challenges to continuous service engagement and maintenance of trust, including:

- Fluctuations in intensity and frequency of service engagement;

- Inconsistent attention to other recovery goals; and,

- Increased burdens on integrating housing supports into case management.

Fluctuations in Intensity and Frequency

Throughout these interim periods, the housing search process was marked by a cyclical course of engagement.For example, some consumers would lose trust that their case managerwas working on their housing search and disengage. This service provider noted: 'If there was a long, long delay, sometimes consumers started refusing to meet with the worker and then they would disappear and then it would be this long gap in service;' while another put it more succinctly: 'if a consumer is unhoused, they're harder to connect with.' This occurred even when the delay was a direct result of a consumer's limiting choice:'He understood that he was looking in a very close area. He did understand that, butthere was a period of time where I noticed he had sort of shut down with me.'This worker commented on a consumer holding steadfast in his choice to live downtown, sayingat times he expressed desperation ('I'll take anything')but subsequently turn down options: 'it was like a roller coaster with him.' Because consumers' hope for housing ultimately lay with their case manager, though, they would eventually re-engage. As this case manager explains,

I've had one or two clients call and say, look, I'm just frustrated...and they say [they] understand... the housing constraints and stuff, but...nobody's dropped out of service because of their lack of access to housing, or the length of time it takes to transfer.

One consumer, initially frustrated by a long delay in accessing housing, requested that his name be removed from the list: 
And then I just forgot about it. Then after about a month and a half, suddenly my worker phoned again. He said, "Listen, do you want to get involved again? We are trying to give you this [housing]." And then I said, "I don't know; phone me next week." And the next week I phoned myself.

Similarly, this housing worker describes how a consumer became "non-communicative with the case manager and with the housing team, because he's kind of upset [at a long delay], but recently, last week, the case manager was able to connect with him and they're going to start looking again.'

Service providers, faced with demanding caseloads, and frustrated at being unable to meet consumer preferences for permanent housing, occasionally fluctuated in their attention levels for pragmatic reasons. The type of interim situation the consumer was in played a role in determining the intensity of their involvement. One case manager described a consumer living with a friend, saying, 'his need wasn't as urgent as other people's...he wasn't on the street anymore.'This housing workercommented:

It was cycle-based. For a given period of time, it would be a real priority with the worker or with the agency. Other times, it's like, 'He's okay right now' and the consumer might be doing okay, but then [there] would be a theft of his belongings from his room and then it was, like, heightened again. It was up and down.

Another spoke more generally about the logic process: 'this person is in a long term shelter, they're ambivalent about housing anyway, let's take care of this other person where it's urgent.' Housing workers, collaborating closely with these case managers, offered a similar rationale behind the prioritization process in initial housing:

The agencies would tend to prioritize people in terms of who they wanted to focus the housing on, and that isn't necessarily based on, you know, how long someone has been waiting for housing ... but they're flagged as sort of a priority to house. Maybe they can't go to the shelter system for whatever reason, or they're going to be literally on the street, so the agency will want to focus on that. as well as in rehousing: 
The first priority for transfers was those whose housing was at risk or they were really seriously affected by the housing choice they had ....[if] it's reallyaffecting their health, theirmental health, their emotional well-being, then okay that's a priority and we'll address that. Inconsistent Attention to Recovery Goals

Because consumerswere singularly focused on obtaining permanent housing during this time, they generally interacted with case managers abouttheir housing situation to the exclusion of other service goals. One consumer, for example, was asked about what he was working on with his case manager and replied, 'We're just trying to find the housing and then go from there.'Asked if he was working on any issues, another participant said 'no, we usually just, you know, just talk about finding housing.' Several case managerscommentedthat consumers perceived them solely as housing workers during interim periods: 'So most of our consumers, it's taken them a while for them to see us as non-housing workers, some people still refer to us as housing workers.'Though at times disheartening, they understood why this happened, as this case manager explains:

It shifts the relationship so much that you are viewed as the housing worker...because that is such a huge focus of, of what we've done. Like, right from ground-up, from viewing the apartments, finding the apartments, the lease signings, lease renewals. Arrears. That's such a huge chunk of things.

Nevertheless, they mostly worried that the shift diverted consumers from other important recovery goals: 'sometimes we're just seen as housing workers, so, it's really hard, sometimes, to work on the other stuff, like, work on the trauma, to work on the goals;' and, '[housing] took away so much time in working with the [other] things that we needed to be doing.'

Increased Burdens on Integrating Housing Supports into Case Management

Providing housing supports to consumers is a key component of the HF model, but the volatility of the interim situations increases the burden and complexity of these supports. For example, several case managers found the amount of time associated with providing housing 
supportfor those in interim situations to be greater than originally anticipated. This case manager commented, 'if you had to break down our work into how much housing we do and how much case management we do, it might be shocking. ...'

More than the time demands, though, case managers also felt conflicted about how to advocate for those consumers at risk of eviction or housing instability. Case managers attempted to maintain balance, but frequently struggled to understand the most appropriate response when navigating disputes between consumers and landlords. Case managers saw themselves as advocates for the consumers, but how best to advocate was not clear when it affected their need to maintain a positive relationship with the landlords for that consumer's sake or for that of other consumers in the same building. Following are some sample comments:

We're right in the middle...you find that out when you have your client taken to court, you say well, what side am I going to take here?If I go to the client, the landlord might be upset and withdraw or if I go to the landlord, what about the client?... So we kind of have our wings clipped. We can't advocate without fearing the consequences.

It is in the service of preventing delays or relocations (i.e. interim situations) that clarity in what providing housing supports meansbecomes especially critical. But finding that clarity, and navigating these roles, including the role of consumer advocate, is encumbered both by consumers' vulnerability and the unpredictability of the interim situations.

The unique volatility of interim situations, and the singular focus on accessing promised permanent housing, affected the capacity to maintain trust and continuous service engagement. Specifically: 1) consumer and staff satisfaction with the interim housing situation and staff's multiple competing demands contributed to fluctuations in intensity and frequency of service engagement; 2) interest in and capacity to address non-housing recovery goals flagged; and 3) 
the need for housing supports, and for clarity in how best to advocate for consumers during disputes or negotiations with landlords, increased.

\section{DISCUSSION}

, HF housing placement data in Toronto reflect those from many other cities, with about one-fifth of consumers experiencing delays in accessing initial housing of four months or more, and about one-third relocating or requesting a transfer within the first year of housing.Recruited among these groups, all our study participants, had diverse experiences with interim housing situations. The demand for interim housing exceeded expectations, and resulted in an increased appreciation for the importance ofsafe, affordable interim solutions for some participants.

In Toronto, the demand for interim housing only partially resulted from procedural and market-based issues,such as lack of affordable housing and low vacancy rates, asrespect forconsumer choice contributed significantly to housing delays:consumers often opted for apartments in desirable low-supply downtown locations or requested changes tothoseneighbourhoods once housed due to changes in their personal lives or relationships. While the importance of choice is an issue explored in greater detail elsewhere(Pridham, Zerger et al. 2013),it is noteworthy in this context because if adherence to choice creates the need to address interim situations, it implies that these situations may not be limitations of theHF model, but rather an an important component that merits closer examination. Our study found some consumersexperienced long stays in less than ideal interim housing at least in part because of their particular choices;it is possible that had their choices not been heeded, they would have discontinued their service engagement during this interim period. This is an important area for further exploration. 
On the whole, our findings suggest that consumers waiting for housing lived how and where they had prior to being enrolled in the project: a diversity of settings. For consumers, experiences with interim situations were volatile, and increased feelings ofvulnerability, even when housing delays were due to their particular housing choices. The waiting periods were marked by heightened emotions, with consumers experiencing worsened depression and anxiety or compromised mental and physical health. Although case managers maintained regular contact and continued housing searches throughout these periods, longer delays increased fear among some consumers that they, and their promised housing, would be forgotten. The type and location of interim housing consumers were living in during these waiting periods did have an impact, however: one consumer found his stay in a hotel stressful due to bed bugs and episodes of stolen property; anotherexperienced bouts of depression due to the remote location of his motel and his inability to travel.Service providers, too, experienced greater stress when a consumer was living in these conditions, even though it eased tracking and follow-up. Safe, affordable interim housing could then enhance the HF service model and facilitate the continuity of service engagement.

As the literature indicates, continuous service engagement throughout gaps in housing is critical to the HF model, so it is important to explore how interim situations affect those therapeutic relationships(Stefancic and Tsemberis 2007). Our findings suggest the unique volatility of interim situations, and the singular focus on accessing permanent housing, affected the capacity to maintain trust, continuous service engagement and pursuit of other recovery and rehabilitation goals. Specifically, it contributed to fluctuations in intensity and frequency of service engagement and flagged consumer interest in and case managers' capacity to address non-housing recovery goals. Most consumer participants in this study, for example, stayed 
clearly focused on moving into permanent housing, and vacillated in the intensity of their engagement with their case managers. Understanding these patterns may provide insight into how best to serve consumers requiring interim housing and retain their trust and service engagement throughout.

This study also found that housing supports are especially time-consuming and complicated for those in interim housing situations; as such, it brings to the forefrontthe need to understand how best to integrate housing with other case management supports in HF programs. Case managers in this study generally echoed previous findings that HF case managers experience 'rival demands,' with housing supports provided 'at the expense of treatment services.'(Matejkowski and Draine 2009),p.9. Beyond the time demands, they also experienced role conflicts, expressed as feelings of being 'caught in the middle',most notably when navigating disputes between consumers and landlords.

As noted in the introduction, interim housing is distinct from transitional housing programs requiring consumers to meet prerequisites and focusing on housing readiness; instead, they comprise diverse temporary settings and appear to be a necessary and important element of the HF model for those consumers experiencing delays or requiring relocations. A clear understanding of the role of interim housing, and consumer and case manager needs and experiences during these housing gaps, can inform how to optimize these opportunities and ensure continuous service engagement.This study raises important questions, but future research should build on these findings by more clearly delineating which housing options are best - in which situationsand for whom - and how case managers can most effectively work with consumers to ensure positive, long-term service engagement post-placement in permanent housing. 
This study has several limitations. Our sample, chosen to best respond to our study aims, is drawn from a single large urban center andmay not be generalizable to other settings. Although we implemented numerous mechanisms to ensure reliability and methodological rigor in our recruitment of participants, the final sample is not necessarily representative of all those experiencing delays and relocations in the housing process. Nevertheless, thisstudy raises several important issues related to the largely unexamined role of interim housing in the HF model, areas for future research, and implementation considerations. While the need for interim housing may not be necessary for all HF programs, our study revealed numerous reasons and demands for safe, flexible interim housing options, and pointed to how they may influence continuous service engagement, housing stability and consumer recovery. 


\section{REFERENCES}

(2013). Housing First in Canada: Supporting communities to end homelessness. S. Gaetz, F. Scott and T. Gulliver. Toronto, Canadian Homelessness Research Network Press.

Braun, V. and V. Clarke (2006). "Using thematic analysis in psychology." Qualitative Research in Psychology3: 77-101.

City of Toronto (2007). "What Housing First means for people: Results of Streets to Homes 2007 postoccupancy Research."

Hwang, S., V. Stergiopoulos, et al. (2012). "Ending homelessness among people with mental illness: The At Home/Chez Soi randomized trial of a Housing First intervention in Toronto." BMC Public Health12: 787.

Levitt, A. J., J. J. Jost, et al. (2012). "Impact of chronically street homeless tenants in congregate supportive housing." American Journal of Orthopsychiatry82(3): 413-420.

Lincoln, A. K., S. Plachta-Elliott, et al. (2009). "Coming in: An examination of people with co-occurring substance use and serious mental illness exiting chronic homelessness." American Journal of Orthopsychiatry79(2): 236-243.

Lipton, F. R., C. Siegel, et al. (2000). "Tenure in Supportive Housing for Homeless Persons with Severe Mental Illness." Psychiatric Services51(4): 479-486.

Matejkowski, J. and J. Draine (2009). "Investigating the impact of Housing First on ACT fidelity." Community Mental Health Journal45: 6-11.

O'Connell, M., R. Rosenheck, et al. (2006). "An examination of fulfilled housing preferences and quality of life among homeless persons with mental illness and/or substance use disorders." The Journal of Behavioral Health Services and Research33(3): 354-365.

Padgett, D., L. Gulcur, et al. (2006). "Housing First services for people who are homeless with cooccurring serious mental illness and substance abuse." Research on Social Work Practice16(1): 74-83.

Pearson, C., A. E. Montgomery, et al. (2009). "Housing stability among homeless individuals with serious mental illness participating in Housing First programs." Journal of Community Psychology37(3): 404-417.

Pearson, C. L., G. Locke, et al. (2007). The applicability of Housing First models to homeless persons with serious mental illness: Final report. Washington, D.C., U.S. Department of Housing and Urban Development.

Pridham, K. F., S. Zerger, et al. (2013). "Understanding housing delays and relocations within the Housing First model." Journal of Behavioral Health Services and Research (in review).

Sheehan, D. V., Y. Lecrubier, et al. (1998). "The Mini-International Neuropsychiatric Interview (M.I.N.I.): The development and validation of a structured diagnostic psychiatric interview for DSM-IV and ICD-10." Journal of Clinical Psychiatry59(Supplement 20): 22-33.

Stefancic, A. and S. Tsemberis (2007). "Housing First for long-term shelter dwellers with psychiatric disabilities in a suburban county: A four-year study of housing access and retention." Journal of Primary Prevention28: 265-279.

Stergiopoulos, V. (2012). "Moving from rhetoric to reality: adapting Housing First for homeless individuals with mental illness from ethno-racial groups." BMC Health Services Research12: 345.

Tsemberis, S. (2010). Housing First Manual: The Pathways model to end homelessness for people with mental illness and addiction. Center City, MN, Hazelden.

Tsemberis, S. and R. F. Eisenberg (2000). "Pathways to housing: Supported housing for street-dwelling homeless individuals." Psychiatric Services51(4): 487-193.

Tsemberis, S. J. (2010). Housing First : the Pathways model to end homelessness for people with mental illness and addiction Center City, MN, Hazelden. 